\title{
Canopy structure in savannas along a moisture gradient on Kalahari sands
}

\author{
ROBERT J. SCHOLES*, PETER G. H. FROST $\dagger$ and YUHONG TIAN $\ddagger^{1}$ \\ *CSIR Environmentek, Box 395, Pretoria 0001 South Africa, †Institute for Environmental Studies, University of Zimbabwe, \\ Harare, Zimbabwe, $\ddagger$ School of Earth and Atmospheric Science, Georgia Institute of Technology, Atlanta, GA 30332, USA
}

\begin{abstract}
Measurements of tree canopy architecture were made at six savanna sites on deep, sandy soils, along a gradient of increasing aridity. There was substantial variation in the leaf area estimated within each site, using the same sample frame, but different measurement techniques. The trends in canopy properties in relation to the aridity gradient were consistent, regardless of the technique used for estimating the properties. The effective plant area index for the tree canopy (the sum of the stem area index and the leaf area index (LAI)) declined from around 2 to around $0.8 \mathrm{~m}^{2} \mathrm{~m}^{-2}$ over a gradient of mean annual rainfall from 1000 to $350 \mathrm{~mm}$. Stems contributed $2-5 \%$ of the tree canopy plant area index. Since the tree canopy cover decreased from $50 \%$ to $20 \%$ over this aridity range, the leaf area index within the area covered by tree canopies remained fairly constant at $3-4 \mathrm{~m}^{2} \mathrm{~m}^{-2}$. Tree leaves tended from a horizontal orientation to a more random orientation as the aridity increased. On the same gradient, the leaf minor axis dimension decreased from around $30 \mathrm{~mm}$ to around $3 \mathrm{~mm}$, and the mean specific leaf area decreased from 14 to $5 \mathrm{~m}^{2} \mathrm{~kg} \mathrm{ha}^{-1}$. There was good agreement between LAI observed in the field using a line ceptometer and the LAI inferred by the MODIS sensor on the Terra satellite platform, 2 months later in the same season.
\end{abstract}

Keywords: canopy architecture, LAI, MODIS

Received 9 January 2002; revised version received 8 April 2003 and accepted 1 August 2003

\section{Introduction}

The Kalahari sand-sheet, which occupies 2.5 million $\mathrm{km}^{2}$ in the interior of southern Africa, provides a relatively homogeneous substrate over a wide range of soil moisture regimes. This creates an opportunity to investigate vegetation-climate interactions relatively independent of soil effects, and motivated the concept of the Kalahari transect (Scholes \& Parsons, 1997). The SAFARI 2000 regional experiment aims to understand atmosphere-land surface-human interactions in southern Africa (Swap et al., 2002). It was natural for SAFARI 2000 to use the Kalahari transect as a way to quantify the relationships between the abiotic environment and the vegetation cover, for the sandy substrates that cover about a third of the subcontinent (Otter et al., 2002). In doing so, the high-level products of the newest earth observing satellites (such as the leaf area index (LAI)

Correspondence: Robert J. Scholes, tel. + 2712841 2045,

fax + 2712841 2689, e-mail: bscholes@csir.co.za

${ }^{1}$ Formerly at Boston University. estimates from MODIS on the Terra platform) could be calibrated and validated, an objective of the southern African validation experiment (SAVE) (Privette, 2000).

Most exchange processes between the atmosphere and the land surface are mediated by the plant canopy. Models of the radiation balance, fluxes of water, carbon dioxide and trace gases and the deposition of aerosols, for example, all have canopy properties as fundamental parameters (Sellers et al., 1997). The predictions of spectral reflectance models, ecosystem biogeochemical flux models and climate models are all sensitive to the values of, in particular, the green leaf area they use. A strong argument can be made that the amount of green leaf displayed by the canopy, over time, is the single most important parameter in coupling the land surface to the atmosphere. It is conventionally represented by the LAI, defined as one-sided green leaf area per unit of ground area. Other important parameters, in terms of the effect of uncertainty in their true value on landatmosphere interactions, include the distribution of the leaf area horizontally and vertically into canopies, represented by canopy height and cover respectively, 
and the angular orientation of the leaves. For sparsely sampled biomes such as tropical savannas, the values of these key parameters used in regional or global models have typically been based on a few measurements, widely extrapolated, or on theoretical schemes that seek to predict the canopy properties from energy or carbon balance principles.

Given that tropical savannas, defined as mixed treegrass systems in warm climates, occupy at least a sixth of the global land surface (Scholes \& Hall, 1996), and mixed tree grass systems outside the tropics may add a similar area, it is important for global modeling efforts to reduce the uncertainty relating to their canopy structure parameters. Large areas of the earth's land surface are likely to remain inadequately sampled on the ground with respect to canopy properties. Properties such as the LAI are highly variable in time (within a year, and in response to landcover changes over a period of years to decades) and between locations. Therefore, the most practical approach to estimating the parameters over large regions is to make use of satellite-based remote sensing. The satellite-based estimates, such as those delivered by the MODIS instrument on the Terra and Aqua platforms, strive to represent the parameters as they are measured in the field (Myneni et al., 2002). They use a complex algorithm, with different parameters for each major vegetation structural class ('biome'), one of which is savannas. The algorithm is also sensitive to soil background, making the relative consistency of soils in the Kalahari an advantage. Calibration and validation of these algorithms is a key task in improving our confidence regarding land-atmosphere interactions.

LAI can be estimated in the field using one of two broad approaches. The first involves some form of direct measurement, such as harvesting of the vegetation and measurement of its one-sided leaf surface area, or estimating the leaf mass in a given area through application of allometric equations and then using the specific leaf area (SLA: the one-sided leaf area per unit dry mass) to calculate LAI. The second, indirect method involves measuring the 'gap fraction' (the amount of sky that is visible through the canopy) and then inverting a canopy model to estimate LAI. Note that the second method actually estimates the 'effective plant area index' $\left(\mathrm{PAI}^{*}\right)$, since it includes a contribution from stems as well as from leaves. It is referred to as 'effective' (and denoted with an ${ }^{* \prime}$ ) since it is the leaf area as 'seen' by a beam of solar radiation, according to the assumptions made in the canopy model inversion.

There are a variety of related remotely sensed vegetation indices. The fraction of absorbed photosynthetically active radiation (FPAR: Asrar et al., 1984) is closely related to carbon assimilation by the canopy.
It, in turn, is approximately linearly related to the normalized difference vegetation index (NDVI: Tucker, 1979), a measure of vegetation greenness widely used in remote sensing that has a 30-year history spanning many different sensors and platforms.

The aims of this paper are to (1) document canopy properties in a range of savannas along an aridity gradient in southern Africa; (2) determine the range of in situ estimates resulting from the use of different estimation techniques; and (3) compare the in situ measurements with preliminary estimates from the MODIS system. This paper compares the canopy properties of six sites, all located on the Kalahari sandsheet, on sandy soils many tens of meters deep, ranging from an arid savanna with sparse, low trees to a moist, near-closed, tall woodland. The sites varied in long-term mean annual rainfall from $350 \mathrm{~mm}$ to $1000 \mathrm{~mm} \mathrm{yr}^{-1}$. This paper is a companion to the paper by Privette $e t$ al. (this issue), which deals with canopy structure, including canopy cover, clumping and questions of scale. This paper focuses on LAI and leaf orientation alone, and sets out to explore the confidence that can be assigned to measurements from various sources.

\section{Materials and methods}

The general locations of the sample sites (Table 1, see also location maps in Privette et al. (this issue), and a discussion of vegetation trends in the Kalahari in Scholes et al., 2002) were selected before the expedition, in order to cover the main vegetation types in the 300 to $1000 \mathrm{~mm} \mathrm{yr}^{-1}$ climate range, while remaining on Kalahari sands. Given the sparse network of roads in the Kalahari region, slow progress off-road and absence of permanent surface water, accessibility was a major factor in local site selection. The exact locations were chosen in the field in order to be

- representative of the general landscape (this determination was assisted by the use of Landat 7 paper prints in the field),

- homogeneous at a scale sufficient to allow for the pixel size $(250-1000 \mathrm{~m}$ ) and pointing error (1 pixel) of the MODIS instrument, and

- away from disturbance resulting from proximity to a road, water point or cattle station.

The desire to sample in situ at a spatial scale compatible with the MODIS pixel size determined the sampling strategy within the sites. The different instrument teams chose different sampling strategies, which are illustrated in Privette et al. (this issue). In order to ensure comparability of the data, this paper uses measurements only from the 'medium grid' described 
Table 1 (a) The location of the sites, start date of the 3-day sample and the climate at the nearest weather station recorded in the FAOCLIM database. In the case of Pandamatenga site, a Pandamatenga station is listed, but with a very short record period, so Hwange (Robins Camp) was used instead. (b) The main vegetation characteristics of the sites, summarized from Scholes et al. (2002); see also Privette et al. (this issue)

(a) Location and climate data

Latitude Longitude Altitude

\begin{tabular}{|c|c|c|c|c|c|c|c|c|c|c|c|c|}
\hline Site & Date start & $\left({ }^{\circ} \mathrm{S}\right)$ & $\left({ }^{\circ} \mathrm{E}\right)$ & $(\mathrm{m})$ & Station & $\left({ }^{\circ} \mathrm{S}\right)$ & $\left({ }^{\circ} \mathrm{E}\right)$ & (m) & $(\mathrm{mm})$ & $\left({ }^{\circ} \mathrm{C}\right)$ & $(\mathrm{mm})$ & (days) \\
\hline Kataba & 29-Feb-00 & 15.4389 & 23.2530 & 1084 & Mongu & 15.15 & 23.09 & 1053 & 946 & 21.8 & 1774 & 210.8 \\
\hline Pandamatenga & 03-Mar-00 & 18.6565 & 25.4995 & 1065 & Hwange & 18.36 & 25.57 & 960 & 630 & 22.3 & 1774 & 130.6 \\
\hline Maun 1 & 07-Mar-00 & 19.9241 & 23.5920 & 924 & Maun & 19.59 & 23.25 & 900 & 458 & 22.6 & 1671 & 90.1 \\
\hline Maun 2 & 09-Mar-00 & 19.9149 & 23.5610 & 924 & Maun & 19.59 & 23.25 & 900 & 458 & 22.6 & 1671 & 90.1 \\
\hline Okwa & 12-Mar-00 & 22.4108 & 21.7112 & 1089 & Ghanzi & 21.42 & 21.39 & 1100 & 424 & 20.9 & 1623 & 78.5 \\
\hline Tsane & 15-Mar-00 & 24.1684 & 21.8881 & 1115 & Tsane & 24.01 & 21.53 & 1100 & 350 & 20.5 & 1553 & 73.0 \\
\hline
\end{tabular}

(b) Vegetation description

\begin{tabular}{|c|c|c|c|c|c|}
\hline Site & Structural classification & Dominant tree species & $\begin{array}{l}\text { Crown } \\
\text { cover } \\
(\%)\end{array}$ & $\begin{array}{l}\text { Basal } \\
\text { area } \\
\left(\mathrm{m}^{2} \mathrm{ha}^{-1}\right)\end{array}$ & $\begin{array}{l}\text { Mean } \\
\text { max } \\
\text { height } \\
\text { (m) }\end{array}$ \\
\hline Kataba & Broad-leafed deciduous woodland & Brachystegia spiciformis, B. bakerana & 65 & 8.5 & 8.7 \\
\hline Pandamatenga & Broad-leafed semi-deciduous savanna & $\begin{array}{l}\text { Schiziophyton rautennii, Baikiaea plurijuga, } \\
\text { Kirkia Africana, Pterocarpus angolensis }\end{array}$ & 32 & 6.3 & 11.4 \\
\hline Maun 1 & Broad-leafed deciduous savanna & Colophospermum mopane, Terminalia sericea & 36 & 8.7 & 6.0 \\
\hline Maun 2 & Broad-leafed deciduous savanna & Colophospermum mopane & 32 & 1.2 & 6.0 \\
\hline Okwa & Fine-leafed savanna/shrubland & $\begin{array}{l}\text { Acacia mellifera, Terminalia sericea, Boscia } \\
\text { albitrunca }\end{array}$ & 32 & 1.9 & 2.2 \\
\hline Tsane & Fine-leafed savanna & Acacia luderitzii, A. mellifera, Grewia flava & 14 & 5.3 & 3.7 \\
\hline
\end{tabular}

in Privette et al. (this issue), a $250 \times 300 \mathrm{~m}$ rectangle containing a $6 \times 7$ grid of points spaced $50 \mathrm{~m}$ apart. On the medium grid, the effective PAI was estimated using two approaches: line ceptometer (Decagon Accupar, Pullman, Washington) and plant canopy analyser (Licor LAI-2000, Lincoln, Nebraska). Privette et al. (this issue) has a fuller description of the application of these instruments and the calculation of effective $\mathrm{PAI}^{*}$ from the data they provide.

LAI was also estimated directly by applying speciesspecific allometric relationships between leaf mass and stem cross-sectional area on a tree-by-tree basis within subplots of the medium grid. Leaves from each site were sampled to determine the SLA for conversion of leaf mass to leaf area. Previous trials (Scholes, 1997) in southern African woodlands had shown that the most efficient sampling strategy for estimating tree basal area in large plots was to use a large number $(>30)$ of relatively small-diameter circular quadrats, with the diameter adjusted per site so that each quadrat, on average, included about five trees. In the Kalahari study, the circular quadrats varied from 4 to $8 \mathrm{~m}$ radius, and the number of quadrats was constant at 42 per site, each centred on a node of the $6 \times 7$ medium grid. Thus, in the more densely treed sites, about $11 \%$ of the surface area of the site was sampled. Nevertheless, the standard error of estimation of the basal area was consistent at about $10 \%$ of the mean across all sites. Tree height and circumference just above the basal swelling were measured for all stems within each circular plot.

\section{Leaf dimensions and SLA}

At every site, at least six leaves of each dominant species were collected and pressed. The leaves were collected from different canopies and different positions in the canopy. Once dry, the individual leaves were measured on the long ('major') and short ('minor') axes to the nearest millimetre. The major axis was generally, but not always, in the direction of the leaf midrib, and the minor axis was perpendicular to it. The leaves were then individually weighed, scanned on a flatbed scanner and their area was calculated using Adobe Photoshop (San Jose, California). The SLA was calculated as the one-sided leaf area divided by the airdry leaf mass, including petiole and rachis. Leaves shrink linearly on drying, so the measurements of leaf dimensions will be slightly less than measurements taken on fresh material. The SLA estimates in this paper can be compared with those in Midgely et al. (this 
Table 2 Leaf dimension and specific leaf area for dominant trees and shrubs at the six sampled sites on the Kalahari Transect

\begin{tabular}{|c|c|c|c|c|c|}
\hline \multirow[b]{2}{*}{ Species } & \multicolumn{2}{|c|}{ Leaf axis (mm) } & \multicolumn{3}{|c|}{ Specific leaf area $\left(\mathrm{m}^{2} \mathrm{~kg}^{-1}\right)$} \\
\hline & Major & Minor & Mean & SD & $n$ \\
\hline Brachystegia bakerana & 28.5 & 15.7 & 7.08 & 0.63 & 6 \\
\hline Copaifera baumiana (shrub) & 27.0 & 12.0 & 7.74 & 0.07 & 3 \\
\hline Brachystegia spiciformis & 56.3 & 25.3 & 11.85 & 0.76 & 3 \\
\hline Schinzophyton rautennii & 90.0 & 49.8 & 8.08 & 0.93 & 4 \\
\hline Bauhinia petersiana & 42.2 & 39.3 & 11.32 & 1.17 & 6 \\
\hline Pterocarpus angolensis & 57.8 & 29.3 & 12.15 & 0.31 & 6 \\
\hline Baikieia plurijuga & 45.2 & 21.7 & 11.05 & 1.70 & 6 \\
\hline Baphia massaiensis & 79.7 & 50.0 & 10.32 & 0.39 & 6 \\
\hline Kirkia acuminata & 58.7 & 19.8 & 11.51 & 1.22 & 6 \\
\hline Colophospermum mopane & 66.3 & 30.0 & 10.36 & 0.34 & 3 \\
\hline Lonchocarpus capassa & 75.7 & 46.0 & 8.73 & 0.42 & 3 \\
\hline Terminalia sericea & 66.3 & 20.5 & 5.91 & 0.36 & 6 \\
\hline Acacia mellifera & 8.7 & 4.3 & 5.52 & 1.44 & 6 \\
\hline Grewia flava & 45.3 & 14.8 & 5.34 & 0.94 & 4 \\
\hline Boscia albitrunca & 26.3 & 5.8 & 3.95 & 0.44 & 6 \\
\hline
\end{tabular}

issue), for which the area was determined in the field on hydrated leaves. On average, the SLA recorded here is $9.3 \%$ lower $(n=11)$. The SLA is a relatively constant characteristic in mature leaves of a single species in these savannas, both within and between sites, possibly since there is no high degree of self-shading. Thus, the sample size was sufficient to reduce the standard error of estimation to within $10 \%$ of the mean (Table 2).

\section{Line ceptometer}

The Decagon Accupar instrument consists of a linear array $0.8 \mathrm{~m}$ long of 80 silicon PAR detectors, with associated data capture electronics. The array was positioned horizontally and pointing north, at $1 \mathrm{~m}$ above ground level at each of the 42 grid locations. The probe was set to average and stored the photosynthetic photon flux density (PPFD) in $204 \mathrm{~cm}$ long groups along the array, per exposure. Exposures were only taken during full sun conditions, although there were generally clouds in the sky. A pair of Licor PAR sensors, one with a shadow band, continuously recorded the total and diffuse PPFD above the canopy at a fixed, treeless location within $100 \mathrm{~m}$ of the site. These data were used, in conjunction with the Accupar data, to calculate canopy transmission $(\tau)$.

One set of readings was taken in the early morning or late afternoon, when the solar zenith angle (the angle between the sun and the vertical) was around $67^{\circ}$. At this solar zenith angle, the extinction coefficient of the canopy is almost independent of the angular distribution of leaves within the canopy. The second set was taken around noon. The combination of the two allowed both the effective $\mathrm{PAI}^{*}$ and a rough estimate of the canopy shape distribution to be calculated, using the empirical canopy model described in the instrument manual (Decagon, no date; based on Campbell, 1986). This model approximates the leaf angle distribution in the canopy as the surface of an ellipsoid. The canopy shape parameter is the ratio of the horizontal $(X)$ to vertical $(Y)$ axis of this ellipsoid. A more robust estimate of canopy shape, with an error estimate, would require consideration of a larger number of sun angles.

\section{Plant canopy analyser}

The Licor LAI-2000 plant canopy analyser estimates the gap fraction in five concentric elevation angle bands. The instrument assumes an evenly lit sky within each band, a condition that is approximated when the sky is completely covered by an even, thick cloud layer (seldom the case in the Kalahari) or by the sky conditions immediately before or after dusk or dawn. The measurements reported here were made within $30 \mathrm{~min}$ of either sunrise or sunset. Measurements were made with the sensor close to ground level $(0.1-0.5 \mathrm{~m})$ and a mask over the sensor, blocking the $90^{\circ}$ sector of the view towards the operator (and the setting or rising sun, since the operator always stood with their back towards the sun). Measurements were taken at each of 42 locations, on the same grid as was used for the line ceptometer. Sky irradiances in each of the bands were simultaneously collected by an identical instrument, at a location with no canopy cover within a few hundred metres of the site. 


\section{Allometry}

The leaf area supported by a tree is typically highly correlated with the cross-sectional area of the tree stem. Strong relationships also exist between stem crosssection, height and woody biomass. Many such relationships have been developed for southern Africa (Rutherford, 1979; Scholes, 1987; Goodman, 1990; Shackleton, 1997), but most are in the 'grey literature'. These relationships have been compiled and re-analysed by Netshiluvhi \& Scholes (2001). For the species where no allometric information is available (which constitute a small proportion of the leaf biomass on the sites) the following equation, based on the generalized relationship that emerged from the pooled relationships, was used:

$$
L=0.1 A
$$

where $L$ is leaf mass ( $\mathrm{kg} \mathrm{DM}$ ) and $A$ is the crosssectional area of the stem $\left(\mathrm{m}^{2}\right)$. Leaf area per tree is the product of leaf mass and the SLA. Minor species for which SLAs were not collected were given the default value of $6 \mathrm{~m}^{2} \mathrm{~kg}^{-1}$, a conservative average for semi-arid savannas. The contribution of these species was less than $10 \%$ of the leaf area in all cases.

The woody-plant basal area, leaf area and projected surface area of stems per site were calculated from the data collected on individual stems (species, height and circumference) within the circular plots at each site. Kamatou (2003) has developed an allometric relationship for the prediction of stem area index (SAI) in southern African woodlands. For individual stems

$$
\begin{aligned}
& \text { projected stem area }=0.004 \times \text { diameter }^{1.97}, \\
& r^{2}=0.86, n=165, P<0.001,
\end{aligned}
$$

where the projected stem area is in square metres and the stem diameter at the base is in centimetres. This equation was applied on a stem-by-stem basis to the data from the circular quadrats, and summed on a per unit area basis to obtain an estimate of SAI per site.

\section{Line intercept}

Many lines, each $20-50 \mathrm{~m}$ in length, and adding up to about $300 \mathrm{~m}$ of total length per site, were laid out between the grid points described above. The fraction of the length of each line that had (a) tree canopy directly overhead, and (b) shrub canopy overhead was recorded, along with the tree or shrub species uppermost in each segment. Trees were defined as being taller than $1 \mathrm{~m}$, while shrubs were shorter than $1 \mathrm{~m}$. The distinction between trees and shrubs in this system is somewhat arbitrary. The 'shrub' category often included small individuals of species that also occurred in the 'tree' layer, and some 'shrubs' exceeded $1 \mathrm{~m}$ in height. There is, in some cases, a relatively distinct shrubby layer below the tree layer. Shrubs in this environment are typically multi-stemmed from the base, often with 10 or more stems. Savanna trees are also typically multi-stemmed, although the number of stems is generally less than five.

\section{Water balance}

Rainfall by itself is a poor indicator of water availability to plants, even where the soil is as homogeneous as it is on the Kalahari transect. For instance, rainfall during the cool part of the year is more effective than rainfall in the hot part, and a larger fraction of the rain in medium-sized storms is available to plants than in either very big storms, or very small rainfall events. A simple water-balance model was used to calculate the average number of days per year on which water was available to plants ('Gdays'), based on monthly rainfall and monthly potential evaporation. 'Gdays' are calculated as the sum over the months of the year $(\mathrm{m})$ of the number of days in the month $\left(D_{\mathrm{m}}\right)$ multiplied by the ratio of monthly rainfall $\left(P_{\mathrm{m}}\right)$ to monthly potential evaporation $\left(E_{\mathrm{m}}\right)$. Gdays in 1 month was not allowed to exceed the number of days in the month. Rainfall in excess of evaporation in a given month was carried over to the next month as storage within the soil profile, there being effectively zero runoff on these porous sands.

$$
\begin{aligned}
\text { Gdays }= & \sum D_{\mathrm{m}}\left(P_{\mathrm{m}} / E_{\mathrm{m}}\right), \quad \text { subject to } \\
& \text { maximum value of }\left(P_{\mathrm{m}} / E_{\mathrm{m}}\right)=1 .
\end{aligned}
$$

The potential evaporation was calculated using the Penman-Monteith equation, using data available on the FAOCLIM CD-ROM (FAO, 2001).

\section{Results and discussion}

\section{Trends in leaf size and thickness in relation to aridity}

The site-averaged SLA (a measure of leaf thickness) and mean leaf size were calculated by weighting the SLA and leaf minor axis length per species by the contribution of the species to the total tree layer LAI (Tables $3-5)$. Above a moisture index of around 90 Gdays per year (which corresponds to a mean annual rainfall of around $460 \mathrm{~mm}$ on the sandy soils of the transect, and approximately coincides with the lower limit of dryland cropping), the weighted leaf minor dimension and SLA are variable but relatively high at $>20 \mathrm{~mm}$ and $>8 \mathrm{~m}^{2} \mathrm{~kg}^{-1}$, respectively (Table 2, Fig. 1a). Below this level of water availability, leaf size drops steeply, as 
Table 3 Plant area index $\left(\mathrm{PAI}^{*}\right)$, leaf area index (LAI) measured at each site at 42 locations in a $350 \times 300 \mathrm{~m}$ grid, using a variety of techniques

\begin{tabular}{|c|c|c|c|c|c|c|}
\hline \multirow[b]{2}{*}{ Site } & \multirow{2}{*}{$\begin{array}{l}\text { LAI-2000 } \\
\text { PAI* }^{*}\end{array}$} & \multicolumn{2}{|c|}{ Accupar } & \multicolumn{2}{|c|}{ Allometry } & \multirow{2}{*}{$\begin{array}{l}\text { Grass } \\
\text { LAI }\end{array}$} \\
\hline & & PAI $^{*}$ & (SD) & LAI & SAI & \\
\hline Kataba & NA & 1.86 & $(0.11)$ & 1.70 & 0.1 & 0.45 \\
\hline Pandamatenga & 1.01 & 1.56 & $(0.26)$ & 1.68 & 0.12 & 0.42 \\
\hline Maun 1 & 1.21 & 1.28 & $(0.09)$ & 0.74 & 0.09 & 0.13 \\
\hline Maun 2 & NA & 1.46 & $(0.14)$ & 0.13 & 0.02 & 0.13 \\
\hline Okwa & 1.75 & 1.34 & $(0.09)$ & 0.19 & 0.02 & 0.81 \\
\hline Tsane & 0.78 & 0.83 & $(0.10)$ & 0.51 & 0.04 & 0.20 \\
\hline
\end{tabular}

Values in brackets are standard errors of 42 samples. The grass values are modelled estimates based on the rainfall and tree basal area at the sites (see text for details), and refer to the average grass LAI at it highest value during the growing season. During the sampling campaign, the grass LAI was negligible at all sites due to a dry period immediately before the sampling.

NA, not measured; SAI, stem area index.

Table 4 Woody plant cover at each site as measured by line transect (except at Kataba, where for trees it was measured using a spherical densiometer)

\begin{tabular}{lllll}
\hline & \multicolumn{2}{l}{ Trees $>2 \mathrm{~m}$} & & \multicolumn{2}{c}{ Shrubs $<2 \mathrm{~m}$} \\
\cline { 2 - 3 } Site & Transects & Cover (\%) & Transects & Cover (\%) \\
\hline Kataba & Densiometer & 49.3 & $8 \times 20 \mathrm{~m}$ & 28.0 \\
Pandamatenga & $24 \times 50 \mathrm{~m}$ & 51.1 & $8 \times 20 \mathrm{~m}$ & 26.3 \\
Maun 1 & $14 \times 40 \mathrm{~m}$ & 39.6 & $14 \times 40 \mathrm{~m}$ & 33.5 \\
Maun 2 & $14 \times 40 \mathrm{~m}$ & 33.2 & $\mathrm{NA}$ & 23.5 \\
Okwa & & $($ None) & $42 \times 20 \mathrm{~m}$ & 7.2 \\
Tsane & $16 \times 50 \mathrm{~m}$ & 20.0 & $16 \times 50 \mathrm{~m}$ & \\
\hline
\end{tabular}

*At Okwa site, the shrub cover measurement includes the small area covered by trees $>1 \mathrm{~m}$ tall.

NA, not measured.

Table 5 Mean leaf angle at each site as measured by two techniques

\begin{tabular}{lccc}
\hline & Canopy ellipsoid & \multicolumn{2}{c}{ Leaf angle (degrees from horizontal) } \\
\cline { 2 - 4 } Site & $X: Y$ & Accupar & LAI-2000 \\
\hline Kataba & 60.4 & 1 & NA \\
Pandamatenga & 4.27 & 21 & 34 \\
Maun 1 & 2.60 & 32 & 55 \\
Maun 2 & 1.82 & 41 & 40 \\
Okwa & 1.62 & 44 & 58 \\
Tsane & 1.08 & 54 & 72 \\
\hline
\end{tabular}

The Accupar technique estimates the ratio of the horizontal $(X)$ to the vertical $(Y)$ axis of an ellipsoid representing the leaf angle distribution. This ratio can be empirically converted to a leaf angle using the formula leaf angle (radians) $=9.65\left(3+\right.$ ratio) ${ }^{-1.65}$ (Nobel et al., 1993).

NA, not measured.

does SLA. The evolutionary advantage of smalldimension leaves in arid environments has been suggested to be the capacity of small leaves to couple leaf temperature closely to the air temperature (Bate et al., 1982). In large leaves, the leaf temperature is strongly influenced by radiative forcing, which causes the temperature of a sunlit leaf, not effectively cooled by air movement or evaporation, to rise above the 


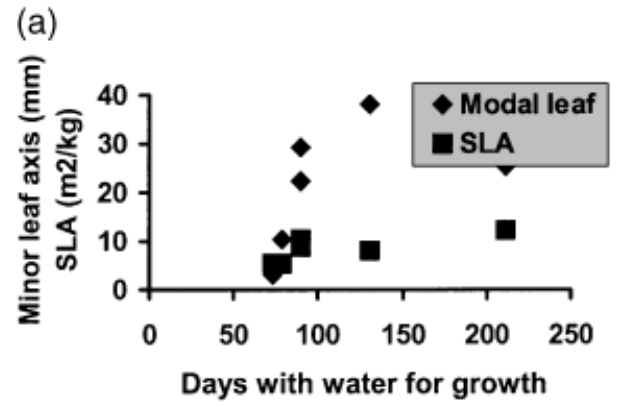

(b)

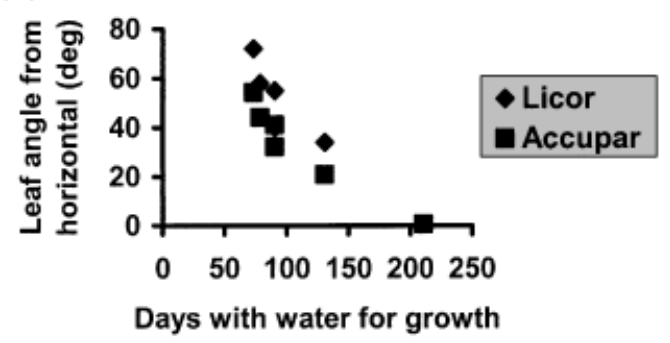

(c)

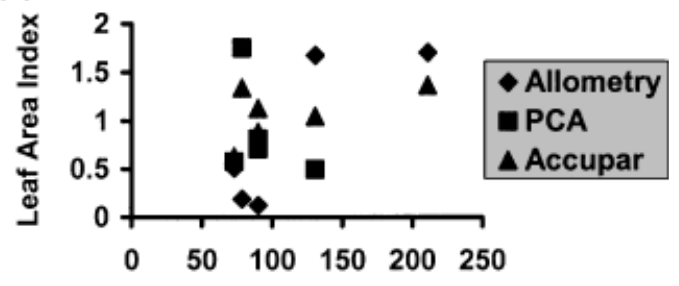

Days with water for growth

(d)

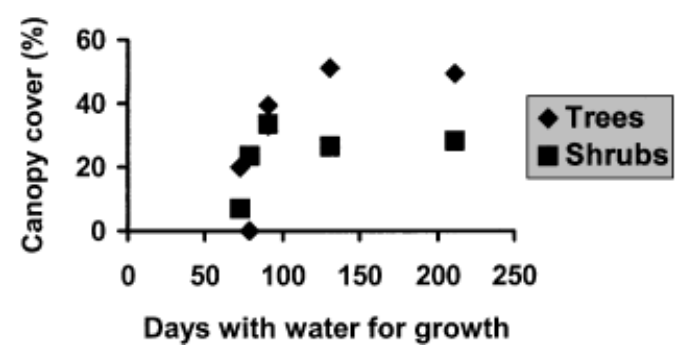

Fig. 1 Canopy parameters in relation to site aridity. The values of leaf size and specific leaf area are the weighted average of species at the site, with the contribution to total site leaf area as the weighting factor. (a) Leaf minor axis length and specific leaf area (b) leaf angle (c) leaf area index (d) woody plant canopy cover.

temperature at which lethal damage occurs (assumed to be above $45^{\circ} \mathrm{C}$ ). Fine leaves are more closely coupled to the atmosphere and thus do not get as hot.

The dominance of relatively thick, rigid (sclerophyllous) leaves is believed to be linked to low water availability: the leaves need to tolerate very low water potentials without collapsing, and this requires rigidity. Sclerophylly in other environments has traditionally been explained in terms of the benefits of leaf longevity in nutrient-poor environments (eg Specht \& Rundel, 1990). The suggestion is that slow turnover of leaves helps to conserve nutrients, but if they are to last more than 1 year, leaves need to be thick and tough to resist the seasonal dry period. The Kalahari environment is relatively infertile, but the more arid sites are relatively more fertile than the moister sites (this is reflected in the leaf nitrogen content: Midgley et al., 2003), so the prevalence of sclerophylly is more likely to be due to the frequent occurrence of intra-seasonal drought. The dominant trees are deciduous across the entire gradient sampled here.

\section{Trends in leaf angle in relation to aridity}

The Accupar ceptometer and the Licor plant canopy analyser agree that the mean leaf angle at the moist sites (which are also closer to the equator) is more horizontal than the mean leaf angle at the arid sites (Fig. 1b). Vertical leaves may be a strategy for avoiding radiation damage during the hottest, mid-day hours. The moister sites may not need this adaptation during the wet season, and shed their leaves in the dry season. Most woody species in the Kalahari have wilting mechanisms that serve to make the leaves more vertical, or fold them in half, under extreme water stress. The 'gland' at the junction of the butterfly-shaped leaf of Colophospermum mopane is an example. If the soil is dry, the two leaflets fold on top of each other, and the entire leaf droops on its petiole, exposing a minimum area to the mid-day sun.

\section{Comparison of methods of estimating leaf area}

The two methods for estimating PAI* based on canopy gap fraction should, in principle, give similar results. Broadly speaking they do, but at some sites there are substantial differences, which may partly be explained by differences in the height at which the samples were taken. The Accupar and LAI-2000 samples were generally taken at exactly the same locations, but the Accupar was held at $1 \mathrm{~m}$, while the LAI- 2000 was held at $10 \mathrm{~cm}$. The LAI-2000 should therefore 'see' more canopy above it than the Accupar; in general, however, the LAI-2000 PAI $^{*}$ values were lower than those produced by the Accupar.

The Accupar sensor is $0.8 \mathrm{~m}$ long, and samples beam radiation directly from the sun, while the LAI-2000 is a point sample integrating over the sky hemisphere. The 'footprint' of a single LAI-2000 sample depends on the vegetation height. At the moist end of the gradient, where the vegetation was close to $10 \mathrm{~m}$ tall, the outer ring of the LAI-2000 would be sampling a radius in 
excess of $25 \mathrm{~m}$; thus the combined footprint covers virtually the entire $250 \times 300 \mathrm{~m}$ sample frame. At the arid sites (Okwa and Tsane) where the vegetation was low, the LAI-2000 measurements sample a much smaller area. In an attempt to avoid problems resulting from an inhomogeneous sample (having half of a given sample point canopy covered, and the other half sky covered), samples were not taken exactly at these sites at the grid-point flag, but taken under the middle of the nearest canopy if the location was considered to be a 'canopy-covered' point, or in the middle of an adjacent open space if considered an 'open' point. This may have been an unnecessary precaution, and may explain the anomalously high $\mathrm{PAI}^{*}$ recorded at Okwa using the LAI-2000.

The algorithms used by the two instruments differ: the Accupar uses a partially empirical algorithm, while the LAI-2000 uses an algorithm more closely related to fundamental principles of canopy light interception, but nevertheless sensitive to assumptions regarding randomness of vegetation elements and the evenness of diffuse sky radiation, both of which are hard to satisfy.

The light-interception methods estimate PAI* rather than LAI, since they are unable to distinguish between light interception by stems and light interception by leaves, and are dependent on the canopy model that they assume. The fraction of light intercepted by stems rather than leaves is expected to increase as the aridity increases and the LAI decreases. The increased 'stemminess' of shrubs relative to trees is well documented (eg Rutherford, 1982). At the moist end of the transect, the stem SAI is estimated at about $0.1\left(5 \%\right.$ of the $\left.\mathrm{PAI}^{*}\right)$, while at Tsane at the dry end it is estimated to be 0.04 (also 5\% of $\mathrm{PAI}^{*}$ ). At the two shrubby sites (Okwa and Maun 2) it is estimated to be $0.02\left(1.5 \%\right.$ of $\left.\mathrm{PAI}^{*}\right)$. This may be because the SAI algorithm was not developed specifically for shrubby plants, and underestimates the projected stem area of small-diameter stems. Asner (1998) estimates SAI to be 0.2 to 0.4 in savannas in Texas. The SAI measured with the Accupar instrument at a South African savanna site (Skukuza), receiving $600 \mathrm{~mm}$ of rain with a basal area of $7 \mathrm{~m}^{2}$ ha ${ }^{-1}$ and mean tree height of 9, was 0.1 (Scholes et al., 2001; Kamatou, 2003).

The allometric method for calculating leaf area does not suffer from these sampling and stem area contamination problems, but is critically dependent on the validity of the allometric relationships available, which is hard to assess. The allometric relationships assembled by Netshiluvhi \& Scholes (2001) include dozens of species (including the dominants from all the sites), but were determined at locations often very far from the sites at which they were applied. Furthermore, at shrubby sites they were applied to stems with diameters smaller than the stems used to establish the relationship. This tends to underestimate the leaf area supported, as is apparent in the low allometric estimate of leaf area for at Okwa and at Maun 2. The Okwa site is underlain by calcrete, promoting a shrubby growth form, while the Maun 2 site has a coppiced growth form due to harvesting of trees for poles and fuelwood, and the presence of a pan depression within the study area.

For the analyses that follow, the Accupar ceptometer $\mathrm{PAI}^{*}$ data are taken to represent the sites, since the methodology was entirely consistent for this instrument throughout the study. The PAI Accupar values are converted to LAI by subtracting the estimated SAI.

\section{Trends in leaf area in relation to aridity}

The LAI measured using the Accupar instrument was the LAI of the woody plants taller than $1 \mathrm{~m}$. The LAI of grasses and shrubs can make a significant contribution to total LAI in this environment, particularly in the relatively open, shrubby sites such as Okwa River and Tsane. Unusually high rainfall had been experienced south of Maun in the 3 months preceding the expedition, and the resultant grass growth was exceptional. By the time the expedition reached the Okwa and Tsane sites, however, a month of hot, dry weather had been experienced and the grass had already wilted, curled and partly turned brown. Therefore, at the time of sampling the green, live LAI of all the sites was more than $90 \%$ due to the woody plant LAI recorded here. This value is not necessarily representative of other years, but is likely to be representative of the LAI measured by satellite 2 months later in the same year, since no substantive rains followed our visit.

A post hoc estimate of the peak contribution of grass LAI can be made using known relationships between rainfall and grass production (Table 3 ). In the absence of tree cover, the wet season aboveground grass production on sandy soils similar to those in the Kalahari, is approximately

$$
\text { AGGNPP }_{\text {no trees }}\left(\mathrm{kg} \mathrm{ha}^{-1}\right)=1.32 \times \text { rainfall }-1196
$$

(Dye \& Spear, 1982). The presence of trees greatly reduces this quantity to a degree substantially greater than would be inferred directly from the tree cover. Simplifying from Scanlan (1991) suggests an approximate equation

$$
\mathrm{AGNPP}_{\text {with trees }}=\mathrm{AGNPP}_{\text {no trees }} \mathrm{e}^{(-k \times B A)},
$$

where $k$ has a value between 0.2 and 0.4 (declining with increasing grass production in the absence of tree cover), and BA is the site woody plant basal area $\left(\mathrm{m}^{2} \mathrm{ha}^{-1}\right)$. The values for grass peak LAI in Table 3 
assume a grass SLA of $10 \mathrm{~m}^{2} \mathrm{~kg}^{-1}$ (Scholes, 1987; Scholes \& Walker, 1993).

Satellite-based LAI or greenness estimates are unable to distinguish between tree and grass components within a pixel at a single time. If multi-temporal data are available, some inference regarding the relative contribution can be made from their different phenology and interannual variability. It is estimated that the contribution of grasses to the total LAI is about $20 \%$ at most of the sites, dropping to $10 \%$ under the dense $C$. mopane cover at Maun and reaching $37 \%$ at the sparsely wooded Okwa site. When the grass and tree LAI are summed, the peak LAI at all sites is in the region of 2.02.5. Differences in productivity between the sites are therefore due to differences in leaf area duration, rather than peak LAI.

The decrease in woody plant LAI with increasing aridity is consistent with the findings of the North Australia tropical transect (NATT) (Williams et al., 1996), but for a given mean annual rainfall, the LAI on the Kalahari transect was higher than the LAI recorded in northern Australia. The use of a more robust index of aridity for making this intercontinental comparison (such as the water balance index used in this study) may remove some of this difference, but there may be fundamental differences between the two environments relating to soil fertility, fire regimes or the degree of concentration of rainfall within the year.

\section{Agreement with satellite-based estimates}

The MODIS instrument measures reflectance in 32 wavebands in the visible, near-infrared and thermal bands, with a pixel size ranging from 250 to $1000 \mathrm{~m}$, and daily coverage. Global estimates of LAI at $1 \mathrm{~km}$ resolution, based on algorithms using up to seven of these bands, are a standard high-level MODIS product. The estimates are made every 8 days using pooled cloud-free daily data.

The algorithm used by MODIS to derive LAI is based on the inversion of a complex, multi-spectral canopy radiation model, parameterized separately for six 'biomes', one of which is savanna. In practice, the algorithm consults a series of look-up tables for the given biome, rather than performing the full model inversion for each pixel. This makes the product 'model independent' in the sense that another model could be used to generate the look-up table, but of course the results for a given product are dependent on the model used. If insufficient multi-spectral data are available for the period, a back-up method based on relationships between the NDVI and LAI are used together with a biome classification map (Myneni et al., 2002).

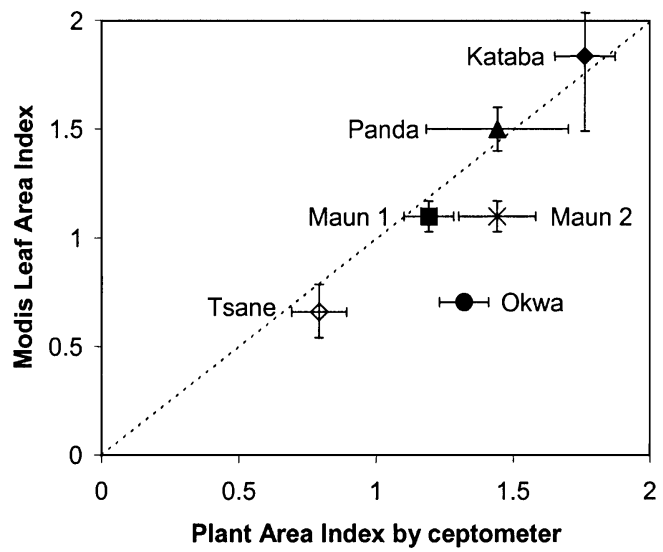

Fig. 2 Leaf area index (LAI) product from MODIS for May 2000 vs. the LAI measured in situ using the Accupar ceptometer. The 1:1 line is superimposed. Error bars are the standard deviation of 25 pixels centred on the site in the case of MODIS and 42-point measurements in the case of the ceptometer.

The instrument was launched in December 1999, but the first trial LAI products are only available from May 2000. Although this is 3 months after the field sampling, the tree leaves were still on the canopy in May. The grasses would have browned off to an even greater extent than they had at the time of ground sampling, but green grass LAI was a small part of site LAI at the time of sampling. Therefore, the May 2000 images are believed to be comparable with the ground sample of tree leaf $\mathrm{PAI}^{*}$ taken in March 2000. Figure 2 shows the agreement between the ground sample and the satellite-based estimates. Each MODIS LAI estimate in this paper is an averaged value from 25 pixels surrounding the ground sample point. The satellite estimate is approximately 5\% higher than the Accupar ground sample at the moist end of the gradient (Kataba), and 16\% lower at the dry end (Tsane). The low satellite estimates of LAI for the two shrubby sites were conspicuously low relative to the ground measurements. For the Maun 2 site, covered with coppiceform C. mopane, the mid-day leaf-folding mechanism in this species can cause the apparent LAI to be lower than the actual LAI during periods of water stress. This may have been the case during the 10:30 hours overpass of the satellite in May.

\section{Conclusions}

There are clear trends in woody plant canopy properties with increasing aridity in the Kalahari environment. Leaf area and canopy cover decrease and the leaf angle becomes progressively less horizontal as the rainfall decreases from 1000 to $300 \mathrm{~mm} \mathrm{yr}^{-1}$. The tree LAI defined with respect to the ground area within the 
canopy perimeter is fairly constant across the rainfall gradient at around 4; and the peak total system (grass plus shrub plus tree) LAI is suggested to be fairly constant at around 2. At the arid extreme most of this peak is due to grass leaf area, which is of short duration. Leaf size and SLA decrease suddenly below a rainfall level of $460 \mathrm{~mm} \mathrm{yr}^{-1}$, equivalent to about 90 days of growth opportunity. Satellite recovery of leaf area is within the range of uncertainty of ground estimates, where the uncertainty is defined as the range of estimates from in situ measurements that results from using different measurement techniques.

\section{Acknowledgements}

The work reported in this paper was part of the SAFARI 2000 experiment. R.J.S. was supported by funds from the South African Department of Arts, Culture Science and Technology LEAD programme called SAFARI 2000.

\section{References}

Asner GP (1998) Biophysical and biochemical sources of variability in canopy reflectance. Remote Sensing of Environment, 64, 234-253.

Asrar G, Fuchs M, Kanemasu ET et al. (1984) Estimating absorbed photosynthetic radiation and leaf area index from spectral reflectance in wheat. Agronomy Journal, 76, 300-306.

Bate GC, Furniss PR, Pendle PG (1982) Water relations in southern African savannas. In: Ecology of Tropical Savannas. Ecological Studies 42 (eds Hunley BJ, Walker BH), SpringerVerlag, Berlin.

Campbell GS (1986) Extinction coefficients for radiation in plant canopies calculated using an ellipsoidal inclination angle distribution. Agricultural and Forest Meteorology, 36, 317-321.

Decagon (no date). AccuPAR Lear PAR/LAI Ceptometer (Model PAR-80) Operators Manual. Version 3. Decagon, Pullman, WA.

Dye PJ, Spear PT (1982) The effects of bush clearing and rainfall variability on grass yield and composition in southwestern Zimbabwe. Zimbabwe Journal of Agricultural Research, 20, 103118.

FAO (2001) FAOCLIM: World-wide Agroclimatic Data (CD-ROM). Food and Agriculture Organisation, Rome.

Goodman PS (1990) Soil vegetation and herbivore relations in Mkuze Game Reserve, Natal. PhD Thesis, University of Witwatersrand, Johannesburg.

Kamatou GP (2003) Determination of the growth of the trees at the tower flux site at Skukuza, Kruger National Park. Masters Dissertation, University of the Witwatersrand, Johannesburg.

Midgley GF, Aranibar JN, Mantlana KB et al. (2003) Photosynthetic and gas exchange characteristics of dominant woody plants on a moisture gradient in an African savanna. Global Change Biology, (this issue).

Myneni RB, Knyazikhin Y, Privette JL et al. (2002) Global products of vegetation leaf area and fraction of absorbed PAR from year one of MODIS data. Remote Sensing of Environment, 83, 214-231.
Netshiluvhi TR, Scholes RJ (2001) Allometry of South African woodland trees. Report ENV-P-I 2001-007, CSIR, Pretoria.

Nobel PS, Forseth IN, Long SP (1993) Canopy structure and light interception. In: Photosynthesis in a Changing Environment (eds Hall DO, Scurlock JMO, Bplhar-Nordenkampf HR, Leegood RC, Long SP), Chapman \& Hall, London.

Otter LB, Scholes RJ, Dowty P et al. (2002) The southern African regional science initiative (SAFARI 2000): wet season campaigns. South African Journal of Science, 98, 131-137.

Privette JL (2000) Southern African validation of NASA's earth observing system (SAVE EOS). Proceedings of 28th International Symposium on Remote Sensing of Environment. Cape Town, South Africa. CD-ROM.

Privette JL, Myneni RB, Knyazikhin Y et al. (2002) Early spatial and temporal validation of MODIS LAI product in Africa. Remote Sensing of Environment, 83, 232-243.

Privette JL, Tian Y, Roberts G et al. (this issue) Structural characteristics and relationships of Kalahari woodlands and savannas. Global Change Biology (this issue).

Rutherford MC (1979) Aboveground biomass subdivisions in woody species of the savanna ecosystem project study area. SANSP Report 36, CSIR, Pretoria.

Rutherford MC (1982) Annual production fraction of aboveground biomass in relation to plant shrubbiness in savanna. Bothalia, 14, 139-142.

Scanlan JC (1991) Woody overstorey and herbaceous understorey biomass in Acacia harpophylla (brigalow) woodlands. Australian Journal of Ecology, 16, 521-529.

Scholes RJ (1987) Response of three semi-arid savannas on contrasting soil types to removal of the woody component. PhD Thesis, University of the Witwatersrand, Johannesburg.

Scholes RJ (1997) Measuring woodlands. Report ENV-P-I 98018, CSIR, Pretoria.

Scholes RJ, Gureja N, Giannecchinni M et al. (2001) The environment and vegetation of the flux measurement site near Skukuza, Kruger National Park. Koedoe, 44, 73-83.

Scholes RJ, Parsons DAB (eds) (1997) The Kalahari transect: research on global change and sustainable development in Southern Africa, 61 pp. IGBP Report 4, IGBP Secretariat, Stockholm.

Scholes RJ, Walker BH (1993) An African Savanna: Synthesis of the Nylsvley Study. Cambridge University Press, Cambridge.

Scholes RJ, Hall DO (1996) The carbon budget of tropical savannas, woodlands and grasslands. In: Global Change: Effects on Coniferous Forests and Grasslands (eds Breymeyer AI, Hall DO, Melillo JM, Agren GI), pp. 69-99. SCOPE/John Wiley and Sons, New York.

Scholes RJ, Dowty PR, Caylor K et al. (2002) Trends in savanna structure and composition along an aridity gradient in the Kalahari. Journal of Vegetation Science, 13, 419-428.

Sellers PJ, Dickinson RE, Randall DA et al. (1997) Modelling the exchange of energy, water and carbon between continents and atmosphere. Science, 275, 502-509.

Shackleton CM (1997) Prediction of woody productivity in the savanna biome of southern Africa. PhD Thesis, University of the Witwatersrand, Johannesburg.

Specht RL, Rundel PW (1990) Sclerophylly and foliar nutrient status of Mediterannean climate plant communities in Southern Australia. Australian Journal of Botany, 38, 459-474. 
302 R. J. SCHOLES et al.

Swap RJ, Annegarn HJ, Otter L (2002) SAFARI 2000 southern African regional science initiative (SAFARI 2000): summary of science plan. South African Journal of Science, 98, 119-124.

Tucker CJ (1979) Red and photographic infrared linear combination for monitoring vegetation. Remote Sensing of Environment, 8, 127-150.
Williams RJ, Duff GA, Bowman DMJS et al. (1996) Variation in the composition and structure of tropical savannas as a function of rainfall and soil texture along a large-scale climatic gradient in the Northern Territory, Australia. Journal of Biogeography, 23, 747-756. 
Copyright of Global Change Biology is the property of Blackwell Publishing Limited and its content may not be copied or emailed to multiple sites or posted to a listserv without the copyright holder's express written permission. However, users may print, download, or email articles for individual use. 